\title{
PENGARUH PELATIHAN KADER JIWA TERHADAP JUMLAH KUNJUNGAN LANSIA DI DESA KARANGBONG KECAMATAN PAJARAKAN KABUPATEN PROBOLINGGO
}

\author{
lin Aini Isnawati ${ }^{1}$, Rizka Yunita ${ }^{2}$ \\ 1 Program Studi Sarjana Keperawatan, Stikes Hafshawaty Pesantren Zainul Hasan \\ 2 Program Studi Profesi Ners, Stikes Hafshawaty Pesantren Zainul Hasan \\ E-mail : 1) iinainiisnawati@gmail.com \\ E-mail : 2) rizkayunita10@gmail.com
}

\begin{abstract}
Elderly can cause a person to experience a decrease in physical strength, speed and skills that resulting in a decline of health functions in term of physically, psychologically and socially. This condition causes the elderly to be hampered in carrying out daily activities. As a result, the elderly feel inferior, easily offended, feel useless, unhappy, lose their roles, and are worthless. Efforts to overcome this problem are by forming a mental health cadre so that they can invite the elderly to conduct health check up at the posyandu. This study aims to analyze the effect of soul cadre training toward the number of elderly visits. This study was used experimental quasy design with one group pre-post test design. This research was carried out in Karangbong Village, Pajarakan District, Probolinggo District. The population and sample of this study were all mental health cadres that is 25 cadre using total sampling. The research instrument was used observation sheets by assessing the number of elderly visits. This study uses data analysis paired t-test. This study shows that there is significant effect of soul cadre training on the number of elderly visits in Karangbong Village, Pajarakan with $\rho$ value of 0,001 . Suggestions from this study are that intervention is needed for the elderly such as supportive therapy in order to provide support and motivation to the elderly so that it can improve the quality of life's welfare physically and psychologically.
\end{abstract}

Keywords : training, soul cadre, elderly visit

\begin{abstract}
Abstrak : Lanjut usia dapat menyebabkan seseorang mengalami penurunan kekuatan fisik, menurunnya kecepatan dan keterampilan sehingga mengakibatkan adanya kemunduran fungsi kesehatan baik secara fisik, psikis, dan sosial. Kondisi ini menyebabkan lansia terhambat dalam melakukan aktifitas sehari-hari. Akibatnya, lansia merasa rendah diri, mudah tersinggung, merasa tidak berguna, tidak bahagia, kehilangan peran, dan tidak berharga. Upaya untuk mengatasi masalah tersebut yaitu dengan cara membentuk kader jiwa agar dapat mengajak lansia untuk melakukan pemeriksaan kesehatan ke posyandu. Penelitian ini bertujuan untuk menganalisis pengaruh pelatihan kader jiwa terhadap jumlah kunjungan lansia. Penelitian ini menggunakan desain penelitian quasy experimental dengan one group pre-post test design. Penelitian ini dilaksanakan di Desa Karangbong, Kecamatan Pajarakan Kabupaten Probolinggo. Populasi dan sampel penelitian ini adalah seluruh kader jiwa sejumlah 25 orang dengan menggunakan teknik yaitu total sampling. Instrumen penelitian menggunakan lembar observasi dengan menilai jumlah kunjungan lansia. Penelitian ini menggunakan analisa data berupa paired $t$-test. Penelitian ini menunjukkan bahwa terdapat pengaruh pelatihan kader jiwa terhadap jumlah kunjungan lansia di Desa Karangbong, Pajarakan dengan nilai $\rho$ value sebesar 0,000 . Saran dari penelitian ini adalah diperlukan intervensi kepada lansia seperti terapi suportif agar dapat memberikan dukungan dan motivasi kepada lansia sehingga dapat meningkatkan kualitas kesejahteraan hidupnya secara fisik dan psikologis.
\end{abstract}

Kata Kunci : pelatihan, kader jiwa, kunjungan lansia

\section{PENDAHULUAN}

\begin{abstract}
Lanjut usia didefinisikan sebagai suatu periode yang menyebabkan seseorang mengalami penurunan fungsi tubuh antara lain berkurangnya kekuatan, kecepatan dan keterampilan dalam melakukan kegiatan sehari-hari sehingga membuat kemunduran kesehatan secara fisik, psikis, dan sosial (Babazadeh et al, 2016). Seperti yang diungkapkan oleh Iparraguirre (2015) menguraikan bahwa pada saat ini, jumlah
\end{abstract}

penduduk lansia telah mencapai angka 500 juta dengan usia rata-rata sekitar 60 tahun dan diprediksi pada tahun 2025 penduduk lansia meningkat mencapai 1,2 milyar.

Semakin bertambahnya jumlah lansia, maka dapat berdampak terhadap tingkat ketergantungan lansia kepada orang lain semakin meningkat pula (Mohapatra, 2011). Lansia mengalami ketergantungan kepada orang lain sebagai akibat dari 
penurunan kesehatan fisik seperti adanya perubahan penampilan dan menurunnya fungsi panca indra sehingga menyebabkan lansia sering kali merasa rendah diri, emosi labil, mudah tersinggung, merasa dilecehkan, kecewa, tidak bahagia, adanya perasaan kehilangan, dan merasa tidak berguna bahkan sampai mengalami depresi (Kashyap \& Sidhu, 2011).

Kondisi fisik dan psikis yang semakin menurun menyebabkan lansia sering kali kurang mampu melakukan pekerjaan secara produktif sehingga membuat mereka merasa tidak berdaya dan putus asa. Di sisi lain, lansia juga tetap dituntut untuk dapat memelihara kesehatannya dan melakukan perawatan terutama kepada lansia yang mempunyai penyakit fisik (Kammar, Kamath \& Ashalatha, 2011). Adanya permasalahan tersebut, lansia sering kali mengabaikan kondisi kesehatannya sebab merasa bahwa penyakit fisik selalu dialami usia lanjut sehingga membuat lansia enggan untuk melakukan kunjungan secara berkala kepada petugas kesehatan (Susilowati, 2014).

Permasalahan tersebut jika tidak diatasi dengan segera maka dapat menurunkan derajat kesehatan lansia baik secara fisik dan psikologis. Salah satu solusi yang dapat dilakukan untuk mengatasi permasalahan tersebut yaitu dengan cara melibatkan masyarakat untuk memelihara kesehatan lansia melalui pembentukan kader jiwa. Tse, Suprojo dan Adiwidjaja (2017) menguraikan bahwa kader jiwa merupakan pilar utama untuk menggerakkan dan mengelola pembangunan kesehatan psikologis masyarakat yang bersifat secara sukarela.

Selain itu, Marchira (2011) juga menambahkan bahwa kader jiwa merupakan pihak utama yang paling dekat dengan masyarakat sehingga dapat mengidentifikasi kesehatan jiwa masyarakat. Menurut Surjaningrum (2012) juga menekankan bahwa dengan adanya kader jiwa maka dapat membantu petugas kesehatan untuk mampu melakukan deteksi dini secara menyeluruh kepada masyarakat terutama lansia yang mengalami penurunan kesehatan baik secara fisik maupun psikologis sehingga dapat diberikan penanganan secara tepat. Berdasarkan hasil studi pendahuluan yang telah dilakukan pada tanggal 15 Februari 2018 di Desa Karangbong, Kecamatan Pajarakan Kabupaten Probolinggo didapatkan bahwa di desa tersebut tidak mempunyai kader jiwa. Selain itu, berdasarkan hasil observasi didapatkan bahwa kunjungan lansia ke pelayanan kesehatan terutama posyandu mengalami penurunan kunjungan setiap bulannya hingga mencapai $68 \%$. Hal ini dikarenakan sebagian besar lansia mengeluh malas, malu, dan pasrah dengan kondisi kesehatannya yang semakin menurun. Mereka menganggap bahwa tidak perlu melakukan pemeriksaan kesehatan sebab kesehatannya tidak semakin membaik. Hal ini menyebabkan lansia merasa tidak berdaya, sedih, tidak berharga, putus asa dan pesimis. Selain itu, kesulitan finansial dan jarak yang jauh juga menjadi penyebab lansia menolak untuk melakukan pemeriksaan kesehatan. Akibatnya, hanya terdapat 18 lansia saja yang melakukan kunjungan rutin ke posyandu setiap bulannya.

Berdasarkan uraian data dan fakta yang telah diuraikan diatas, maka penulis tertarik untuk melakukan pengembangan lebih lanjut mengenai pengaruh pelatihan kader jiwa terhadap jumlah kunjungan lansia.

\section{METODE PENELITIAN}

Penelitian ini menggunakan desain penelitian yaitu quasy experimental dengan one group pre-post test design sehingga seluruh responden penelitan mendapatkan pelatihan kader jiwa. Penelitian ini menggunakan populasi dan sampel yaitu seluruh kader jiwa sejumlah 25 orang sesuai dengan kriteria inklusi dan eksklusi yang telah ditentukan. Penentuan sampel penelitian menggunakan teknik sampling yakni total sampling. Penelitian ini dilaksanakan pada tanggal 1 April 2018 di Desa Karangbong, Kecamatan Pajarakan Kabupaten Probolinggo. Instrumen penelitian ini menggunakan lembar observasi dengan menilai jumlah kunjungan lansia di posyandu. Setelah peneliti mendapatkan data, selanjutnya peneliti melakukan analisa data menggunakan uji pairedat-test.

\section{HASIL PENELITIAN}

\section{Karakteristik Responden}

Berikut ini adalah uraian hasil dari distribusi frekuensi karakteristik demografi responden penelitian sebagai berikut : 
Tabel 1. Distribusi Frekuensi Karakteristik Responden Kader Jiwa

\begin{tabular}{lcc}
\hline Karakteristik & $\mathbf{n}$ & (\%) \\
\hline Usia (tahun) & 5 & 20 \\
27 - 30 th & 11 & 44 \\
31 - 34 th & 7 & 28 \\
$35-38$ th & 2 & 8 \\
38 - 42 th & & \\
Jenis Kelamin & 6 & 24 \\
Laki - laki & 19 & 76 \\
Perempuan & & \\
Pendidikan & 4 & 16 \\
SD & 8 & 32 \\
SLTP/Sederajat & 12 & 48 \\
SMU/Sederajat & 1 & 4 \\
PT & & 4 \\
Pekerjaan & 1 & 12 \\
Karyawan Swasta & 3 & 28 \\
Wiraswasta & 7 & 56 \\
Petani & 14 & \\
lbu Rumah Tangga & & \\
\hline
\end{tabular}

Berdasarkan pada tabel di atas didapatkan hasil bahwa sebagian besar responden berumur $31-34$ tahun yaitu sebanyak 11 responden (44\%) dan sebagian kecil responden berumur 38 - 42 tahun yaitu sebanyak 2 responden (8\%). Sementara itu, responden kader jiwa mayoritas adalah berjenis kelamin perempuan yaitu sebanyak 19 responden $(76 \%)$ sedangkan laki-laki hanya berjumlah 6 responden (24\%). Selain itu, sebagian besar responden memiliki pendidikan mayoritas SMU / Sederajat yaitu sebanyak 12 responden (48\%) dan sebagian kecil memiliki pendidikan perguruan tinggi yaitu hanya sebanyak 1 responden (4\%). Sedangkan pekerjaan responden sebagian besar adalah ibu rumah tangga yaitu sebanyak 14 responden $(56 \%)$ dan sebagian kecil responden mempunyai pekerjaan sebagai karyawan swasta yaitu sebanyak 1 responden $(4 \%)$.

\section{Pengaruh Pelatihan Kader Jiwa Terhadap Jumlah Kunjungan Lansia}

Tabel 2. Pengaruh Pelatihan Kader Jiwa Terhadap Jumlah Kunjungan Lansia

\begin{tabular}{cccc}
\hline Jumlah Kunjungan Lansia & Pre-test & Post-test & \multicolumn{1}{c}{$\mathbf{O}^{\prime}$} \\
\hline Mean & 1,2 & 2,48 & $-1,240$ \\
SD & 0,663 & 0,586 & 0,970 \\
Min & 0 & 2 & 2 \\
Max & 2 & 4 & 1 \\
\hline Sig.(2 tail) & & $\alpha=0,000$ & 0,05 \\
\hline
\end{tabular}

Berdasarkan tabel di atas didapatkan bahwa jumlah kunjungan lansia selama sebulan pada saat sebelum dilakukan pelatihan kader jiwa memiliki nilai mean sebesar 1, 2 dengan standar deviasi senilai 0,663 . Sedangkan jumlah kunjungan lansia pada bulan berikutnya setelah dilakukan pelatihan kader jiwa mempunyai nilai mean sebesar 2,48 dengan nilai standar deviasi sebesar 0,586. Dengan demikian, dapat diketahui bahwa setelah diberikan pelatihan kader jiwa, skor rata-rata jumlah kunjungan lansia mengalami peningkatan sebesar 1,240. Selain itu, mempunyai nilai signifikansi sebesar $\rho$ value $=0,000$ sehingga nilai $\rho \leq 0,05$. Oleh karena itu, maka dapat disimpulkan bahwa terdapat pengaruh pelatihan kader jiwa terhadap jumlah kunjungan lansia di Desa 
Karangbong Kecamatan Pajarakan Kabupaten Probolinggo.

\section{PEMBAHASAN}

\section{Pengaruh Pelatihan Kader Jiwa Terhadap Jumlah Kunjungan Lansia}

Berdasarkan data pada tabel 2 didapatkan data sebelum dilakukan pelatihan kader jiwa jumlah kunjungan lansia memiliki rata - rata skor sebesar 1,2 dengan standar deviasi 0,663 sedangkan sesudah diberikan pelatihan kader jiwa, jumlah kunjungan lansia mempunyai skor rerata sebesar 2,48 dengan standar deviasi sebesar 0,586. Sementara itu, nilai signifikansinya sebesar $\rho=0,000$ sehingga $\rho \leq 0,05$ artinya terdapat pengaruh pelatihan kader jiwa terhadap jumlah kunjungan lansia secara bermakna.

Hasil penelitian tersebut sesuai dengan pernyataan yang diungkapkan oleh Kemenkes (2012) bahwa kunjungan lansia dapat didefinisikan sebagai suatu bentuk kegiatan yang dilakukan oleh individu yang mengalami usia lanjut sebagai tindakan dengan tujuan untuk memelihara dan meningkatkan taraf kesehatan dan kesejahteraan hidup baik fisik, sosial, dan psikologis yang dilakukan secara terencana dan berkelanjutan. Selain itu, Guerra, Torres, Gandara, Alonso dan Borrego (2015) juga menekankan bahwa apabila jumlah kunjungan seseorang ke pelayanan kesehatan rendah merupakan evaluasi bagi seluruh pihak termasuk tenaga kesehatan dan juga layanan kesehatan sehingga sangat diperlukan adanya upaya dan kerjasama dengan lintas sektor dalam memberikan dorongan dalam bentuk kegiatan yang dapat meningkatkan pengalaman, pengetahuan dan juga keterampilan melalui memberikan pelatihan kepada kader agar mampu menjalankan tugas dan fungsinya.

Pernyataan tersebut juga serupa dengan yang disampaikan oleh Rosiana, Setyaningrum dan Azizah (2016) yang menguraikan bahwa membentuk kader jiwa merupakan hal yang sangat penting sehingga kader dapat memberikan stimulus kepada masyarakat mengenai pentingnya memelihara kesehatan bukan hanya berfokus kepada fisik saja akan tetapi juga harus memperhatikan kesejahteraan kesehatan psikologis pula juga merupakan hal paling utama.

Kader jiwa merupakan seseorang yang bersedia dengan sukarela untuk membantu masyarakat menyelesaikan segala bentuk permasalahan kesehatan jiwa yang diakibatkan oleh beberapa masalah seperti adanya masalah gangguan jiwa, masalah psikososial yang disebabkan karena bertambahnya usia, pensiun, konflik didalam keluarga serta diakibatkan karena bencana seperti tsunami dan gempa serta bencanabencana lainnya (Rosiana, Himawan \& Sukesih, 2015).

Berdasarkan data penelitian yang telah dilakukan di atas memperlihatkan bahwa adanya peningkatan kunjungan lansia ke posyandu jiwa ini menunjukkan adanya komitmen dari kader jiwa dalam mendorong dan memfasilitasi lansia supaya dapat kontak dengan kesehatan dalam meningkatkan derajat kesehatannya terutama psikologis. Berdasarkan hasil wawancara kader jiwa terhadap lansia yang berkunjung ke posyandu jiwa didapatkan data bahwa lansia sering kali mengalami susah tidur dan mudah marah apabila mengalami masalah didalam keluarga. Selain itu, berdasarkan hasil wawancara didapatkan bahwa salah satu faktor yang paling utama menyebabkan lansia susah tidur adalah ketika lansia mengalami perbedaan pendapat dan konflik dengan anak-anaknya sehingga meningkatkan beban pikiran pada lansia. Hal ini menyebabkan lansia seringkali memendam perasaan dan enggan untuk bercerita dengan anggota keluarga yang lain untuk menghindari konflik. Selain itu, para lansia juga mengalami masalah finansial sehingga mereka kesulitan memenuhi kebutuhan sehari-hari termasuk untuk memelihara kesehatannya.

Menurut Rosiana, Setyaningrum dan Azizah (2016) menguraikan bahwa dengan adanya peningkatan pengetahuan dan keterampilan kader jiwa dalam mengidentifikasi segala bentuk permasalahan yang ada di masyarakat, maka dapat menjadi pedoman dan acuan untuk meningkatkan dan menciptakan derajat kesehatan masyarakat yang optimal. Adanya hasil identifikasi yang dilakukan sedini mungkin merupakan salah satu cara yang tepat untuk menyelesaikan segala permasalahan kesehatan di masyarakat tentunya melalui adanya keaktifan dari kader jiwa.

Hal serupa juga disampaikan oleh Kasmel dan Andersen (2011) juga menekankan bahwa peningkatan status kesehatan di masyarakat tidak bisa terlepas dari adanya peran serta dari masyarakat itu sendiri. Pemberdayaan masyarakat sebagai bentuk kemitraan terhadap pelayanan kesehatan menjadi metode untuk mengaktifkan program-program kesehatan kepada masyarakat (Laverack, 2006). Selain itu, WHO juga menekankan bahwa peran serta masyarakat dalam program kesehatan menjadi salah satu bagian terpenting dalam pemberian intervensi dalam bentuk pencegahan, kuratif dan rehabilitasi (Christens, 2012). 
Pemberdayaan masyarakat yang Kader jiwa dalam masyarakat merupakan hal yang sangat penting sebab kader dapat dikatakan sebagai alat kesehatan masyarakat. Melalui kader, kasus-kasus yang tidak pernah terungkap sebelumnya di masyarakat dapat dilakukan identifikasi sehingga dapat membantu di dalam peningkatan derajat kesehatan (Iswarawanti, 2010).

Melihat hal tersebut, maka kehadiran kader potensial untuk penanganan kesehatan jiwa terutama pada lansia. Lansia merupakan kelompok umur yang rentan terhadap gangguan kesehatan jiwa terutama perubahan fungsi fisik dan sosial. Lansia mengalami perubahan peran didalam keluarga, menurunnya empati keluarga dan teman, beresiko tinggi mengalami perilaku kekerasan, rentan menghadapi masa pensiun, menurunnya kemampuan mencari kebutuhan finansial, rekreasi, keamanan, transportasi, pendidikan, dan beresiko tinggi untuk dititipkan ke panti jompo (Mohapatra, 2011).

Dengan demikian, lansia membutuhkan bantuan masyarakat dalam meningkatkan

\section{DAFTAR PUSTAKA}

Babazadeh, T., Sarkhoshi, R., Bahadori, F., Moradi, F., Shariat, F., Sherizadeh, Y. (2016). Prevalence of depression, anxiety and stress disorders in elderly people residing in Khoy, Iran (20142015). J Anal Res Clin Med, 4(2): 122128.

Christens, B. D. (2012). Targeting empowerment in community development: A community psychology approach to enhancing local power and well-being. Community Development Journal, 47(4): 538-554.

Guerra, C. D., Torres, J. M. C., Gandara, A. R., Alonso, A. M \& Borrego, M. A. R. (2015). Programmed home visits by nursing professionals to older adults: prevention or treatment. Rev. Latino-Am. Enfermagem, 23(3): 535-542.

Iparraguirre, J. (2015). Predicting the prevalence of loneliness at older ages. United Kingdom.

Iswarawanti, D. N. (2010). Kader Posyandu: Peranan dan Tantangan Pemberdayaannya dalam Usaha Peningkatan Gizi Anak Di Indonesia. Manajemen Pelayanan Kesehatan, 13(4): 169-173.

Kammar, M. R., Kamath, R., Ashalatha, k. V. (2011). Functional Abilities of the Aged. Indian Journal Of Gerontology, 25(1): 41-50. tercermin dengan cara membentuk kader jiwa. kesehatannya sehingga diperlukan adanya kader jiwa yang mampu memberikan dukungan dan motivasi kepada lansia untuk menggunakan pelayanan kesehatan dasar.

\section{KESIMPULAN}

Kesimpulan dari penelitian ini adalah terdapat pengaruh pelatihan kader jiwa terhadap jumlah kunjungan lansia di Desa Karangbong Pajarakan Probolinggo dengan nilai signifikansi sebesar $\rho=0,000$.

\section{SARAN}

Saran dari penelitian ini adalah memberikan intervensi kepada lansia salah satunya dengan memberikan terapi suportif sehingga dapat memberikan dukungan dan motivasi kepada lansia untuk dapat meningkatkan dan mempertahankan kesejahteraan hidupnya baik secara psikologis dan fisik.

Kashyap, S., Sidhu, R. (2011). A study of health and subjective well being of the aged. Indian Journal Of Gerontology, 25(1): 111-122.

Kasmel \& Andersen. (2011). Measurement of Community Empowerment in Three Community Programs in Rapla (Estonia). Int. J. Environ. Res. Public Health, 8, 799-817.

Kementerian Kesehatan Republik Indonesia. (2012). Situasi dan analisis lanjut usia. Jakarta: Kemenkes RI.

Laverack, G. (2006). Improving health outcomes through community empowerment: A review of the literature. J Health Popul Nutr, 24(1): 113-120.

Marchira, C. R. (2011). Integrasi kesehatan jiwa pada pelayanan primer di Indonesia: Sebuah tantangan di masa sekarang. Jurnal Manajemen Pelayanan Kesehatan. 14(3): 120-126.

Mohapatra, T. (2011). Problems of Elderly Widows in Odisha: An Empirical Study. Indian Journal of Gerontology, 25(1): 89110.

Rosiana, A., Himawan, R., Sukesih. (2015). Pelatihan kader kesehatan jiwa Desa Undaan Lor dengan cara deteksi dini dengan metode klasifikasi. The 2nd University Research Coloquium, 591598. 
Rosiana, A., Setyaningrum, Y., Azizah, N. (2016). Ipteks bagi masyarakat (ibm) kelompok kader kesehatan jiwa di Desa Pasuruhan Kidul Kabupaten Kudus dalam upaya pemberdayaan kader kesehatan jiwa untuk meningkatkan kemandirian dengan metode "one volunter one patient". The 4th Univesity Research Coloquium, 458-465.

Surjaningrum, E. R. (2012). Gambaran Mental Health Literacy Kader Kesehatan. Insan, 14(3): 194-202.
Susilowati. (2014). Faktor-faktor yang mempengaruhi kunjungan lanjut usia ke posyandu lanjut usia Desa Tegalgiri Nogosari Boyolali. Universitas Muhammadiyah Surakarta: Fakultas Ilmu Kesehatan.

Tse, A. D. P., Suprojo, A., Adiwidjaja, I. (2017). Peran kader posyandu terhadap pembangunan kesehatan masyarakat. Jurnal IImu Sosial dan IImu Politik, 6(1): 60-62. 